\title{
Sex Trafficking, Law Enforcement and Perpetrator Accountability
}

\author{
Holly Burkhalter
}

\begin{abstract}
In theory, everyone - except for criminals involved in their exploitation - agrees that children must not be in the sex industry and further, that those who prey on them must be prosecuted and punished. Virtually every country in the world has adopted national laws prohibiting the commercial sexual exploitation of children. International law is clear on this point, as well. Yet, when governments - and NGOs working with them - take action to extract children from commercial sex venues, common ground on protecting children from abuse can quickly erode with concerns about the efficacy of police intervention, the possibility of collateral harm to consenting adult sex workers or a decrease in access to HIV-prevention and related health services. The author argues that healing this divide must come through the reform of local police and that, without the participation of law enforcement, there can be no long-term protection for children vulnerable to trafficking and related exploitation. In this article, human rights practitioner Holly Burkhalter argues that healing this divide must be accomplished through the reform of local police - and that human rights advocates, local governments and others seeking to combat trafficking cannot achieve long-term, sustainable protection for children without the involvement of law enforcement.
\end{abstract}

Key Words: trafficking, children, law enforcement, accountability, impunity, protection, "raid and rescue" 
In 2010, reports indicated that, Cambodian military police rounded up sex workers in random sweeps and kept them in jail - often abusing them - until their pimps paid bribes to secure their release. ${ }^{1}$ In the same year, the Cambodian anti-trafficking police identified and rescued 21 trafficking victims from brothels and arrested 17 suspected perpetrators.

These two factual descriptions of police behaviour towards adults and children in the sex industry in the same country help explain why human rights advocates disagree passionately about the role of police operations in securing relief for sex trafficking victims. Sex worker advocates support local groups that deny police access to brothel neighbourhoods. Anti-trafficking advocates, for their part, demand that the police enforce the law by removing children and forced adults from commercial sex venues and arresting and prosecuting pimps, brothel owners and traffickers.

The consequence of this tension over the role of law enforcement in commercial sex venues is that rescue for children on the one hand and harm reduction for non-coerced adults on the other are now seen by some partisans on both sides of the divide as mutually exclusive.

As an international human rights activist with 30 years in the field, I have never seen this tension with respect to any other human rights abuse. Whether the crime is rape, genocide, domestic violence, labour slavery or war crimes, human rights advocates have always demanded victim protection and perpetrator accountability. I am not aware of any other case in which human rights organisations have demanded a virtual zone of impunity for perpetrators, where laws may not be enforced and victims are denied protection.

The fact that some human rights activists take this position with respect to children in prostitution can perhaps be explained by their conviction that no law enforcement at all in commercial sex venues offers better protection for vulnerable women and children than poor law enforcement.

Human Rights Watch, Off the Streets: Arbitrary detention and other abuse against sex workers in Cambodia, July 2010. 
It is vitally important to heal this divide between human rights advocates. The solution, I believe, is in the reform of local police. So long as malicious police prey on vulnerable women in the sex industry and are themselves complicit in trafficking of children, they will not be seen as the solution, but the problem. And indeed, under those circumstances, they are.

We need a replicable model of professional policing where the rescue of children and arrest of perpetrators is carried out without harming non-coerced adults co-mingled with them. Fortunately, several promising models are currently being tested, studied and replicated.

One example is in Cambodia itself. When International Justice Mission (IJM) began working in Cambodia in 2002, the open sale of prepubescent girls for sex was wholly tolerated by authorities. There were virtually no arrests and convictions of those who sold children as young as four to sex tourists. The police, including the special anti-trafficking unit, were complicit in the exploitation of children. In 2002, for example, the unit "rescued" a number of minor Vietnamese girls from Phnom Penh brothels, and then promptly arrested them for immigration violations. Some of the girls were taken from the police station and returned to the brothels by the police themselves. ${ }^{2}$ This is a perfect example of abuses committed in the context of supposed "rescue" that has generated cynicism about the possibility of a legitimate law enforcement response to the crime of sex trafficking.

Yet nine years later, things are very different in Cambodia's sex industry. While police investigators still occasionally find a 13 or 14-year-old in a massage parlour or brothel, the routine sale of young children on the streets of Phnom Penh, Siem Reap and other cities has ended. Over 100 trafficking perpetrators have been convicted and jailed; deterrence is growing throughout Cambodia. Politics still plays a toxic role in the protection of perpetrators: witness the December 2011 official pardon and release of three European pedophiles convicted of raping dozens of boys and girls. On the other hand, Cambodia recently charged and convicted four perpetrators, including a high-level police officer on corruption charges for their protection of brothels offering girls for sexual exploitation. It is the first time, to my knowledge, that

2 Human Rights Watch, Cambodia: Young trafficking victims treated as criminals, 23 June 2002. 
Cambodian police have been willing to go after one of their own for such crimes in that nation.

What has been the impact of the increased police activity in brothel areas on non-coerced adult sex workers? IJM staff and contacts in Phnom Penh and elsewhere in Cambodia have not seen increased abuses in the context of legitimate law enforcement. The police unit responsible for the vast majority of children rescued and perpetrators apprehended since 2003, the Anti-Human Trafficking and Juvenile Protection Task Force (AHTJP) of the Cambodian National Police has carried out the rescue of sex trafficking victims and the apprehension of perpetrators without abusing non-coerced adults in the same establishments. ${ }^{3}$ When reports emerged of random sweeps and other police misconduct towards non-coerced adults in 2010, IJM contacted the sex worker union Women's Network for Unity (WNU) in order to learn whether AHTJP police were involved in the abuses. The AHTJP were not specifically identified in any of the complaints and denunciations of police misconduct.

The takeaway from Cambodia is that it is possible to conduct effective and humane law enforcement to rescue children from prostitution without abusing non-coerced adults in the sex industry. The reason this is possible is because of the professionalism and leadership of the AHTJP.

Notwithstanding this outcome, International Justice Mission has received criticism for collaborating with the police to rescue children from prostitution.

In a University of Pennsylvania Law Review article characterising IJM as "neo-abolitionist", author Janie Chuang posits that rescue does more harm than good to victims, who, she writes, might find it preferable to remain in the brothels. ${ }^{4}$

3 The specialised anti-trafficking unit in Phnom Penh prior to this time was not dependably professional, as seen in the unit's response to the 2002 case mentioned here. However, the author is of the view that, under the leadership of General Bith Kim Hong, who assumed command of the AHTJP in 2007, the unit has become highly professional and respectful of human rights, not only on IJM-assisted cases but child sexual exploitation cases generally.

4 J Chuang, 'Rescuing Trafficking from Ideological Capture: Prostitution reform and anti-trafficking law and policy' University of Pennsylvania Law Review, vol. 158: 1655 at p. 1716. 
Journalist Noy Thrupakew, who authored a two-part critique of International Justice Mission in The Nation Magazine, found fault with police activity to remove children as young as five and six years old from brothels in Cambodia in 2003. Thrupkaew writes: 'Those [children in prostitution] who remained or returned to Svay Pak faced an additional challenge: according to Sainsbury, pimps believed that local HIV-education and social work NGOs had aided IJM and the police, and after the raids cut off the groups' access to the women and barred them from providing care. ${ }^{5}$

Her criticisms encapsulated those most common of child rescue and of IJM, suggesting that increased police activity angered brothel owners and pimps, who retaliated by reducing the access of health service providers to women and children in the sex industry.

What is interesting about this view is that anti-trafficking NGOs (in this case, IJM) and the police are blamed for the presumed disruption in services, not the brothel owners and pimps who are actually responsible. The accompanying demand is that IJM and the police should not rescue children because of the possibility that criminals who sell them for sex will become angry and impede the work of service providers, or at a minimum, weigh the risks of diminished health services when determining whether to take minors out of brothels. This view suggests that there is some level of backlash by brothel owners against health workers that would justify leaving the children to their fate.

Contrary to the claims of critics, IJM is supportive of health services for all who need them, including consenting adults in the sex industry, though we cannot control the response of frustrated brothel owners when they lose their youngest money-makers. Thankfully, it does not appear to be an actual problem: despite efforts to obtain confirmation of the allegations that child rescue puts consenting adults at risk, I have not seen credible reports of diminished service in brothel areas where IJM has been active, much less health data to support the claims.

Nonetheless, the spurious notion that child rescue from brothels increases the risk of HIV for adults has been damaging to the work of child protection. Human Rights Watch, for which I served as Washington Director and Advocacy Director from 1983 to 1996, has

5 N Thrupkaew, 'The Crusade against Sex Trafficking', The Nation, 5 October 2009. 
published numerous reports on sex trafficking and, in the past, has always called for law enforcement to free victims and hold perpetrators accountable. ${ }^{6}$ Yet when I consulted HRW about IJM's planned antitrafficking programme in Cebu, the Philippines, antipathy to law enforcement on the grounds that it would undermine AIDS prevention was so strong that researcher Joe Ammon urged the organisation to drop the plan altogether and fund a sex worker union. ${ }^{7}$

The most serious criticism of police activity in commercial sex venues derives from police abuse against sex workers. A 2009 report by the Open Society Institute, Rights Not Rescue describes gross abuses of the rights of men, women, and transgendered people in the sex industry in southern Africa. Violence is often associated with brothel raids or street sweeps in which sex workers are both lawfully or unlawfully arrested and detained. In South Africa, there were reports of police using rubber bullets and spraying sex workers' genitals with pepperspray. ${ }^{8}$

Such abuses cry out for perpetrator accountability, including jail time for police who assault, rape, and otherwise abuse sex workers.

Although IJM does not work in the countries covered in the OSI report, our experience in Cambodia and the Philippines suggests that encouraging the police to enforce anti-trafficking laws and remove coerced adults and minors from commercial sex venues does not inevitably lead to violent abuse of sex workers.

IJM's programme in Cebu, funded by the Bill and Melinda Gates Foundation in 2007, offered IJM the opportunity to commission an independent prevalence baseline before starting its collaboration with local authorities. The baseline study indicated that upwards of six per cent of those being offered for sex in brothels, massage parlours and karaoke bars were minor girls. In addition, before launching casework activities, IJM engaged in extensive consultation with local NGOs and

6 See, for example, Asia Watch (now Human Rights Watch) and Women's Rights Project, A Modern Form of Slavery: The trafficking of Burmese women and girls into brothels in Thailand", 1 February 1994.

7 Ibid.

8 J Arnott and A-L Crago, Rights not Rescue: Female, male, and trans sex workers' human rights in Botswana, Namibia, and South Africa, Open Society Foundations, June 2009, http://www.soros.org/initiatives/health/focus/ sharp/articles_publications/publications/rights_20090626/rightsnotrescue_ 20090706.pdf. 
government health workers who provide HIV prevention and other services to women in the sex industry. We also met with sex workers themselves to discuss the issue of police abuse as well as access to health care.

Over the next three and a half years, the Philippines National Police in Cebu worked with IJM to investigate the commercial sexual exploitation of children and prosecute perpetrators. IJM also collaborated with the Philippines Department of Social Welfare and Development to provide expert care, schooling and job placement for the minor girls (under the age of 18) removed from the brothels. IJM social workers also offered assistance to adult women who were collaterally affected when brothels or bars they worked in were closed for offering children for exploitation.

Throughout the project, IJM conducted quarterly focus group meetings with service providers and collected data from government clinics that serve sex workers. The data indicated no decrease in the number of women receiving services during this period of vastly increased law enforcement operations in the area.

Moreover, IJM's interlocutors observed no increase in abuses by police against adult sex workers in the project area. Police misconduct is highly unlikely in IJM-assisted operations for several reasons. First, IJM provides extensive training to police with whom we collaborate. Proper treatment of non-coerced adults is emphasised, including clear orders to treat all those in a commercial sex venue under investigation, including non-coerced adults, with respect. Second, IJM protocols call for the organisation's own social workers and lawyers to accompany the police on operations. This accompaniment has many benefits. It benefits the children being removed from commercial sex venues because they are assisted by female social workers, who accompany them throughout the legal process thereafter and secure high quality after-care services. The presence of IJM also minimises the possibility of unprofessional actions by the police, who know what the protocols are and follow them.

Within the first three years of the project, 225 trafficked girls and women were rescued and 87 suspected traffickers arrested. An independent prevalence survey at the end of three years revealed a 79

9 A Jones, R Schlangen and R Bucoy, An Evaluation of the International Justice Mission's "Project Lantern": Assessment of five-year impact and change in the public justice system, 21 October 2010.http://www.ijm.org/sites/default/ files/resources/120610-Project-Lantern-Impact-Assessment-AJ.pdf. 
per cent drop in the availability of minors for sex in commercial establishments. ${ }^{9}$ The success of the Cebu model contributed to a decision by the Philippines government to replicate the model with IJM in two other locations starting this year.

There are several factors that contributed to these welcome outcomes. The most important was the government's creation of the Regional Anti-Trafficking Task Force (RATTF) in July 2009, which underwent extensive training, mentoring and monitoring by IJM. Prior to its creation, the Philippine National Police had a policy of transferring officers between units and jurisdictions on a regular basis, and carefully trained leaders were frequently moved away from the area after developing anti-trafficking expertise. Once this unit was created, the skills stayed on location. There were still occasional shakedowns and sweep-type operations during this period, but not by the special unit and not under the auspices of legitimate anti-trafficking operations. ${ }^{10}$

Specialised anti-trafficking units and excellent training-particularly in collaboration with external human rights advocates-equip law enforcement to do its duty to protect and rescue children and trafficked adults and prosecute perpetrators, without causing collateral harm. One of the few IJM cases in which law enforcement treatment of noncoerced adults did not meet IJM standards is itself a clear example of the value and necessity for close collaboration between human rights advocates and local law enforcement. In 2003, the Thai police conducted an anti-trafficking operation based on unassailable information provided by IJM about the sexual exploitation of children in a brothel. However, IJM investigators, lawyers and social workers were not permitted to accompany the police on the rescue operation. In fact, IJM was not even informed that the operation took place. Police identified and removed seven minor trafficking victims, whom IJM assisted, but they also identified a number of Burmese illegal immigrants whom they subsequently deported, in accordance with Thai law.

Had IJM been permitted to directly support law enforcement prior, during and after the operation, our staff could have reinforced the critical need to separate immigration enforcement from child protection actions. Authorities have the right to enforce national immigration law, but it should never be done in the context of child rescue operations. Law enforcement officials' first duty must be to rescue

10 The Philippines government has entered into a Memorandum of Understanding with IJM, which will be replicating the Cebu model in collaboration with regional anti-trafficking units in Manila and Central Luzon in 2012. 
the victims of sex trafficking in situations in which children are comingled with illegal migrants; effective partnership between the police and NGOs can help ensure that all individuals impacted by a police operation are treated fairly and with dignity.

$$
\text { \#\#\# }
$$

Notwithstanding the professionalisation of police forces and the inroads they have made in combating sex trafficking in some countries, abuse and exploitation of sex workers and protection payment and kickbacks by brothel owners to corrupt police continue to be the norm in many places.

A small number of sex worker unions or associations have played an important role in reducing harm to sex workers. Humanitarian NGOs have reported that sex worker groups have secured such gains as education for their children and access to health services and bank accounts. HIV/AIDS activists have rightly pointed to the important role that sex workers can and do play in protecting themselves and their customers from disease exposure by insisting on consistent condom use. ${ }^{11}$

As a result, some supporters of this work are proposing the services of sex worker groups for something very different: law enforcement. In Thailand, for example, the Thai sex worker organisation EMPOWER issued a report protesting a 2003 police operation that removed seven minor girls from a brothel in Chiang Mai, stating: 'Currently women who work in entertainment places have their own methods of assisting trafficked women, those being forced to work, and those under 18 years.' ${ }^{12}$

Likewise, the DMSC sex worker union in Kolkata runs 33 "Self-Regulatory Boards" (SRBs) that reportedly patrol its red-light district and come to the immediate assistance of girls who are underage or of those coerced into the sex trade. ${ }^{13}$ The union strongly opposes police intervention in

11 See, for example, World Health Organization, 'Thailand's new condom crusade', 2010, http://www.who.int/bulletin/volumes/88/6/10-010610/en/index.html among many others.

12 A report by Empower Chiang Mai on the human rights violations women are subjected to when "rescued" by anti-trafficking groups who employ methods using deception, force and coercion, June 2003.

13 A-L Crago, Our Lives Matter, Open Society Institute, 2008. http://www. soros.org/initiatives/health/focus/sharp/articles_publications/publications /ourlivesmatter_20080724 
the Sonagachi red-light district and has physically interfered with efforts by anti-trafficking police to bring minor girls out of brothels it controls.

The activities of organised sex workers to themselves protect children in brothels are commendable. But these rescue efforts alone have not eradicated the sexual exploitation of minors. In Kolkata, for example, minors are clearly available for sex in the area organised by DMSC. ${ }^{14}$ That should not be surprising: sex worker associations cannot deter violent, criminal activity by organising and registration alone. Nor do they-or can they-play a role in apprehending traffickers, pimps and brothel owners who sell children, much less see them brought to justice under the law.

Critics of a law enforcement approach to combating trafficking do not offer sex worker unions as a substitute for perpetrator apprehension. As a matter of fact, they have not offered any alternative to police operations to apprehend perpetrators and bring them to justice. That is because there are none. Except in cases of war criminals indicted by the International Court, perpetrator accountability-including perpetrator apprehension, prosecution, conviction and punishmentis the exclusive domain of a country's public justice system.

We are left with the question: Can we dispense with perpetrator accountability altogether and eliminate trafficking in the sex industry? IJM's answer is: Absolutely not. Judicial accountability and punishment is crucial for deterring and ending the crime of trafficking - as it is for deterring and combating every violent crime. Individuals who become rich off the bodies of women and children are not restrained in the slightest by the threats of fines, the pleadings of sex worker unions, or public education to teach girls about trafficking. Traffickers are in the business to make money; without the deterrence of potential trial and imprisonment, they have no incentive to deprive themselves of the significant income to be generated from trafficked women and children. IJM has found in every country where we have worked that lesser penalties, such as fines, are meaningless to perpetrators who can easily absorb those costs into business operations that are enormously profitable. 
If sex trafficking is an economic crime, it is also a violent crime. All women, men and children in the commercial sex industry are vulnerable to assault, rape, torture and death. Children and forced adults are especially vulnerable, as they must be subdued and compelled to endure repeated rape. Removing the police from red light areas will eliminate one potential source of violence against adults and children in the sex industry-abusive officers themselves-but they are far from being the only source of harm. Women, men and transsexual people in the sex industry report that they are in constant danger of violence from customers, pimps, brothel owners, madams and traffickers. ${ }^{15}$ If the police are absent, there is no possibility of protection from any other source of violence and abuse. And there will be no protection against those who traffic in the sale of children for sex.

Police complicity in sex trafficking and violence against sex workers is not inevitable, nor is it incurable. Training, specialised units, strong political pressure from donor governments, reformers within local government, public demand for enforcing anti-trafficking laws, and NGO oversight are working real changes in the availability of children for sex in Cambodia and the Philippines.

We need something similar with respect to police violence against sex workers. Police must be trained and monitored and they must be prosecuted when they commit crimes against sex workers. Prompt and humane response to reports of violent abuse by others, such as customers and pimps, must be the norm; holding sex workers harmless for crimes committed against them is essential.

The Open Society Institute describes an example of such an approach in Walvis Bay, Namibia:

Sex workers in Walvis Bay reported very few instances of violence perpetrated by police officers. Furthermore, police addressed sex workers' concerns by helping them with clients who refused to pay or who became abusive. The fact that sex workers can turn to the authorities for assistance reduces the perception that sex workers are easy targets. ${ }^{16}$

15 K Shannon, PhD and J Csete, PhD, 'Violence, Condom Negotiation, HIV/STI Risk Among Sex Workers' Journal of the American Medical Association, vol. 304, no. 5, 2010, 573-574.

$16 \mathrm{~J}$ Arnott and A-L Crago, op. cit. 
Child rescue advocates should use their contacts with the police to demand an end to harassment and abuse of sex workers. For example, IJM conveyed serious concern to high-level contacts within the Cambodian police about the abuses committed against adult sex workers last year. Moreover, IJM's police trainings use protocols that "do no harm" to non-coerced sex workers in the course of apprehending perpetrators and rescuing children and trafficked adults.

For their part, sex worker advocates should end their denunciation of legitimate law enforcement to remove children from commercial sex venues. Sweeps and shakedowns and indiscriminate raids by the police are not the same thing as professional enforcement of the law and rescue of trafficking victims. It is wholly appropriate to condemn the former. It is not appropriate to denounce and undermine the latter.

Professionalisation of the police will take time, but it is attainable. In the meantime, children and trafficked adults being raped for profit should not have to wait until police everywhere in the world have been pronounced good enough to protect them.

Holly Burkhalter currently serves as Vice President for Government Relations at International Justice Mission. She formerly served as the U.S. Policy Director of Physicians for Human Rights and as the Advocacy Director of Human Rights Watch. Email: contact@ijm.org 